\title{
Intermetallics Research in Australia
}

\author{
A.J. Morton \\ CSIRO, Division of Materials Science and Technology, Private Bag 33, Rosebank MDC, Clayton, Victoria \\ 3169, Australia
}

\begin{abstract}
The past two decades have seen alloys based upon intermetallic phases evolve from the status of scientifically interesting materials with a range of attractive properties, combined with overriding disadvantages, to that of the next generation of advanced engineering alloys. This evolution, which has been achieved through a very significant research and development effort on a world wide front, has been driven mainly by aerospace requirements for engineering materials with increased performance at high temperatures. Researchers in Australia were involved in the early scientific studies of intermetallics but have entered the engineering intermetallic alloys field relatively late. This paper presents a review of the contributions made in both areas and includes: the development of ductile intermetallics based on the iron and titanium aluminides; deformation processes in these alloys; order and vacancy effects in the $\mathrm{AB}$ type alloys with the $\mathrm{CsCl}$ structure; and novel processing techniques for intermetallic phase production.
\end{abstract}

\section{INTRODUCTION}

The extensive interest in the ordered intermetallic alloys as a class of materials for engineering applications arises from the particular combinations of physical and mechanical properties exhibited by these alloys which makes them candidates for a range of uses including high temperature service, hard magnets or even dental amalgams. Australian researchers have been active in each of the above categories of intermetallic alloys, ranging from fundamental studies of order and microstructure in alloys based on the equiatomic B2 ( $\mathrm{CsCl}$ structure) aluminides, NiAl, CoAl and FeAl carried out in the 1960s [1-4]; to recent research where sophisticated studies of atomic site occupancy in $\gamma / \alpha_{2}$ titanium aluminides are proceeding alongside the development of titanium aluminides with improved ductility [5-7]. Other activities include the development of hard magnetic alloys based on the RE(FeTM) alloys and their nitrides [8-10]; studies of various silicides for electrical and electronic applications [11-13]; and the use of novel processing methods to produce intermetallics [14-16].

Of the earlier research, the work on the B2 alloys has renewed relevance considering the present sustained efforts to develop these alloys as structural materials and, hence, this work together with some recent related studies will be reviewed briefly first. A review of other current Australian research activities in intermetallics will then be presented with emphasis on alloys for structural applications.

\section{THE B2 INTERMETALLICS}

The ordered intermetallic alloys based on the B2 structure were a subject of research interest in the early sixties at the CSIRO Division of Tribophysics. The technique of solid state (broad line) nuclear magnetic resonance (NMR) spectroscopy was used in pioneering work by West to monitor the changes with composition and heat treatment in the field experienced at aluminium atom sites ( $\mathrm{A}^{27}$ resonance) in alloys based on NiAl, CoAl, FeAl and TiCo [1-3]. These changes were correlated with X-ray lattice parameter measurements and with magnetic susceptibility. Figure 1 shows the results of such NMR measurements alloys near the equiatomic composition for each of the three aluminides after slow cooling from $1273 \mathrm{~K}$. 


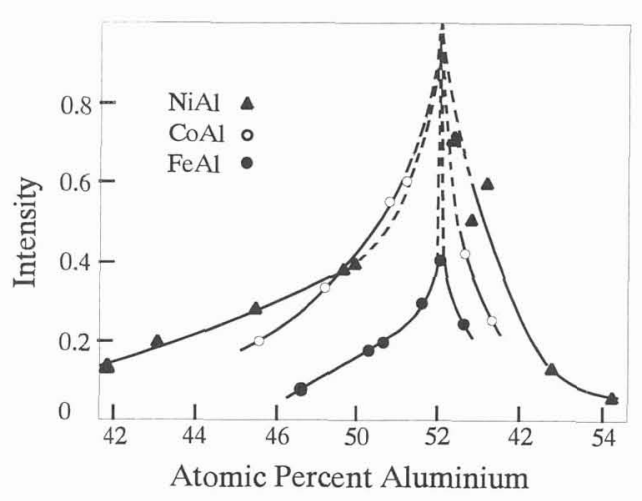

Figure 1. The variation of NMR resonance peak height with aluminium content for $\mathrm{NiAl}, \mathrm{FeAl}$ and CoAl iutermetallic alloys. (West [2])

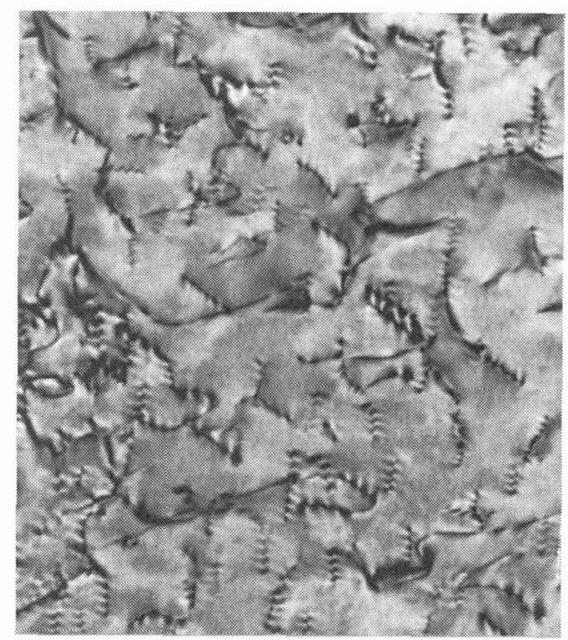

Figure 2. Bright field electron micrographshowing the uniform distribution of dislocations with $b=a<100>$ developed in Fe-50.6at.\% Al after quenching from $1273 \mathrm{~K}$ and annealing at $773 \mathrm{~K}$ for 4 hours. (Morton \& West [4])

Lattice parameter and peak height were maximised at the 50:50 composition and, based on this it wasconcluded that the vacancy defect structure in $\mathrm{NiAl}$ and $\mathrm{CoAl}$ is formed as soon as the aluminium concentration exceeds 50 at. \%, i.e. there was no substitution at all of $\mathrm{Al}$ atoms onto the $\mathrm{Ni}(\mathrm{Co})$ sublattice. A slightly lower NMR signal obtained from air quenched specimens compared to the specimen slowly cooled from $1273 \mathrm{~K}$ indicated that a small degree of disorder was retained by quenching from high temperature [2].

Quite complex results were obtained for alloys based on FeAl with the NMR peak height depending not only on alloy composition but also on cooling rate from the annealing temperature and upon subsequent heat treatment at temperatures in the range 673-573K. These effects were attributed to the retention of a high concentration of vacancies even after slow cooling from $1273 \mathrm{~K}$ and their subsequent elimination at the lower annealing temperatures. Later, transmission electron microscopy (TEM) studies of quenched and annealed FeAl alloys revealed a complex ordering process which supported the suggestion that part of the quenched-in disorder in the Fe-Al system was associated with a high vacancy concentration retained in rapidly cooled B2 structure alloys [4]. In the as-quenched $\mathrm{Fe}-50.6 \mathrm{Al}$ and $\mathrm{Fe}$ 49.3Al (atomic percent) alloys the dislocation density was very low and no evidence of vacancy clusters could be observed even in specimens aged for extended periods at $473 \mathrm{~K}$. However, when quenched specimens were aged at $673 \mathrm{~K}$, the temperature at which the NMR evidence suggested that the quenchedin disorder decreased, there was a very large increase in dislocation density. TEM observations of such specimens during in-situ annealing in a high temperature stage revealed the nucleation of small regions of high dislocation density which then spread throughout the whole specimen. After two hours at $773 \mathrm{~K}$ such specimens contained a dense uniform distribution of dislocations with Burgers vectors of the type $\mathbf{b}=\mathbf{a}<100\rangle$, Figure 2. A detailed mechanism for the generation of these dislocations during the annealing out of the quenched-in vacancy concentration was developed subsequently by Fourdeaux and Lesbats [17]. They proposed that the high density of dislocations was produced by repeated cycles of the reactions:

i) dissociation of $a<100>-->a / 2<111>+a / 2<111>$ dislocations; 


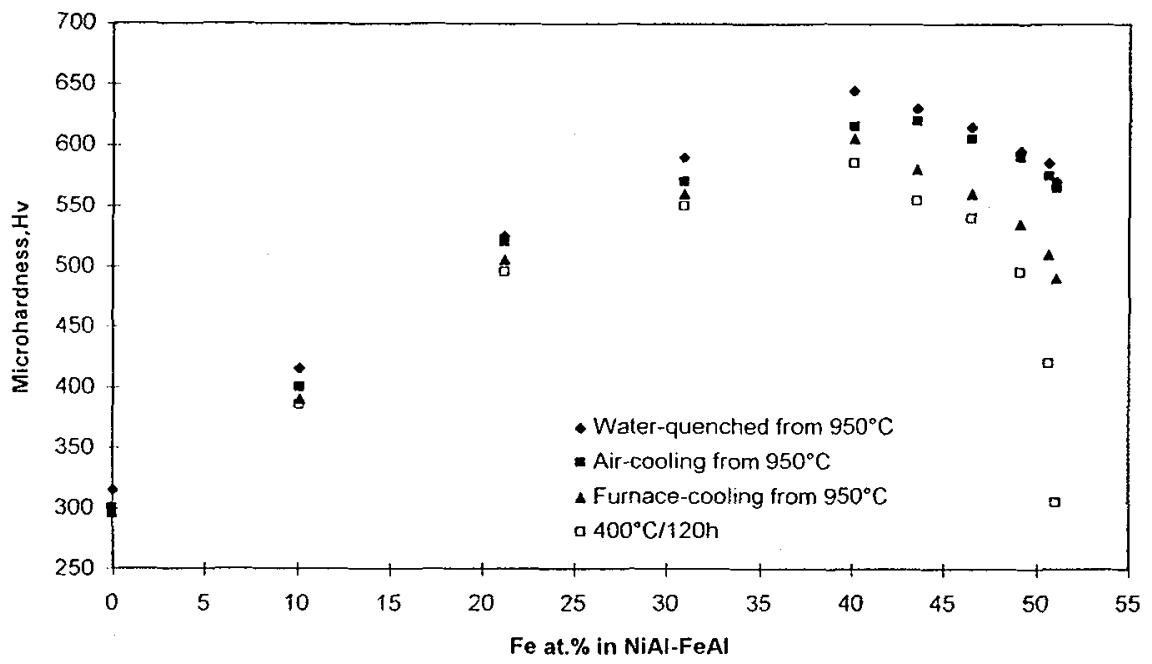

Figure 3. Variation of microhardness of pseudobinary NiAl-FeAl alloys with composition and heat treatment. (Kong and Munroe [19])

ii) climb of $a<111>$ dislocations by vacancy absorption and;

iii) recombination of the climbed dislocations to give $\mathbf{b}=\mathbf{a}<100\rangle$ dislocations.

This mechanism was proposed as a means of eliminating the quenched-in vacancy concentration in strongly ordered alloys where the nucleation of vacancy clusters is difficult except at an existing defect.

Vacancy effects in $\mathrm{Fe}_{1-\mathrm{x}} \mathrm{TM}_{\mathrm{x}} \mathrm{Al}$ alloys $(\mathrm{TM}=$ transition metal) were the major thrust of a recent detailed study by Kong et al. [18-22] from the University of New South Wales. They studied the effects of heat treatment across the pseudo binary system FeAl-NiAl. As shown in Figure 3, they found that the decrease in hardness associated with the annealing out of excess thermal vacancies was a maximum for $\mathrm{FeAl}$ and was essentially zero for $\mathrm{NiAl}$. As little as 1 at. \% Ni addition had a very significant effect on the vacancy related hardness. Despite these effects, the equilibrium hardness of the alloys after long term annealing at $673 \mathrm{~K}$ was a maximum for the alloy $\mathrm{Fe}_{40} \mathrm{Ni}_{10} \mathrm{Al}_{50}$. Small additions of the other transition elements $\mathrm{Co}, \mathrm{Cu}, \mathrm{Mn}, \mathrm{Ti}$ and $\mathrm{V}$ all affected the vacancy related hardening behaviour of the FeAl alloys but $\mathrm{Ni}$ and $\mathrm{Ti}$ were the most potent in increasing the equilibrium hardness. The defect microstructure of the alloys as observed by TEM was consistent with the hardness behaviour in that alloys with marked decrease in vacancy related hardness on $673 \mathrm{~K}$ annealing showed the generation of the high density of $<100>$ dislocations during this treatment as reported previously by Morton and West [4]. In contrast, no such behaviour was observed in alloys with more than $10 \% \mathrm{Ni}$. Such alloys were found to contain a significant density of sub-grain boundaries $\left(\mathrm{Fe}_{30} \mathrm{Ni}_{20} \mathrm{Al}_{50}-\mathrm{Fe}_{10} \mathrm{Ni}_{40} \mathrm{Al}_{50}\right)$ or voids (NiAl).

\subsection{Related Alloys}

The B2 structure of the iron aluminides extends over a wide range of compositions down towards $\mathrm{Fe}_{3} \mathrm{Al}$. Intermetallics based on this composition are not strictly $\mathrm{B} 2$ aluminides but, when ordered, there is essentially a continuous transition between the $\mathrm{B} 2$ structure at $\mathrm{FeAl}$ and the $\mathrm{DO}_{3}$ structure of $\mathrm{Fe}_{3} \mathrm{Al}$. There has been a concerted research effort, notably by ORNL in the United States, to develop iron aluminides as commercial alloys utilising the light weight and excellent oxidation resistance of these alloys. However, for alloys $>28$ at. \% Al, two problems have remained; low ductility at room temperature and moisture related environmental susceptibility causing further reduced ductility.

CSIRO's approach to these problems has been to develop an understanding of their causes and to devise alloying and processing strategies to overcome them. On this basis several series of alloys have been investigated with ternary and quaternary element additions to base alloys with compositions over the range from $15-30$ at. $\% \mathrm{Al}$. The mechanical properties (ultimate tensile strength, tensile elongation and 
hardness) of these alloys were correlated with the deformation microstructure as observed by TEM. An alloy with tensile elongation of $22-25 \%$ and corrosion resistance equivalent to the standard ferritic grades has been developed as a light weight stainless steel. The critical feature of the microstructure for this alloy is obtained by adjusting the composition and processing to produce a disordered alloy in which deformation occurs by the movement of single $1 / 2<111>$ dislocations rather than coupled pairs of $1 / 2<111>$ dislocations.

This alloy is not susceptible to moisture related effects, has superb oxidation resistance and initial trials indicate that it is readily weldable.
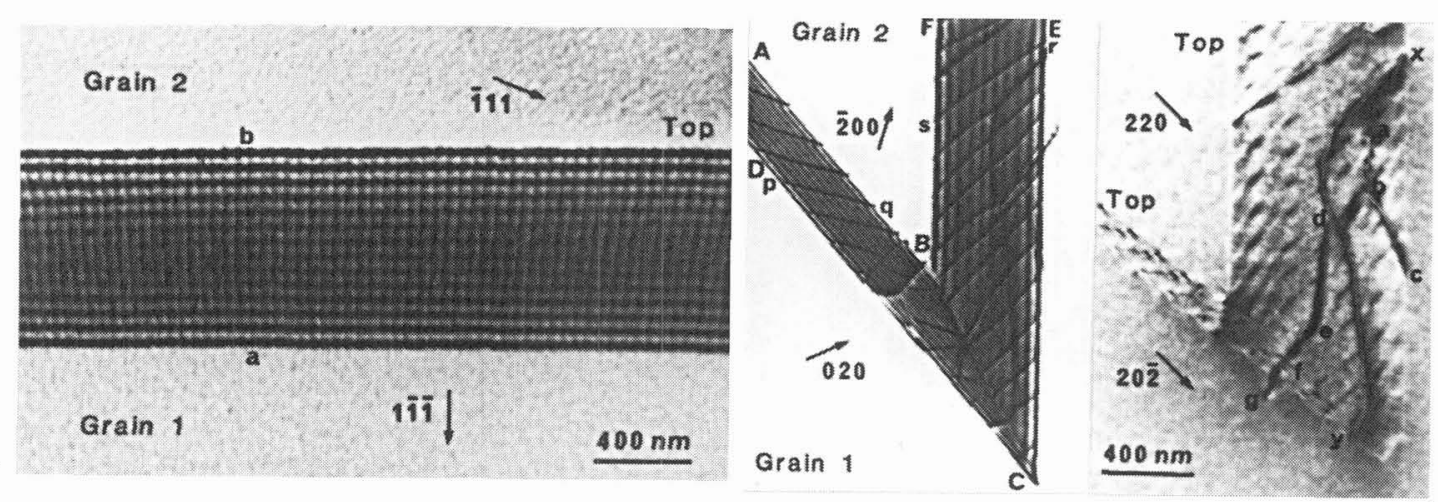

Figure 4. $\Sigma 39$ and $\Sigma 3$ grain boundaries in $\mathrm{Ni}_{3} \mathrm{Al}$ containing GBD's with Burgers vectors characteristic of the relevant DSC lattice for the ordered $\mathbf{L l}_{2}$ structure. (Forwood and Gibson [29])

\section{GRAIN BOUNDARY STRUCTURE IN ORDERED INTERMETALLIC ALLOYS}

The phenomenon of the extraordinary effect of trace boron additions on the ductility of polycrystalline $\mathrm{Ni}_{3} \mathrm{Al}$ alloys has been studied by several workers over the past decades $[23,24]$. Various theories for the boron ductilisation have been generated. These all depend on segregation of the boron to the grain boundaries and range from the generation of disorder at the grain boundaries $[25,26]$ to purely electronic structure effects with the boron occupying interstitial positions in the lattice and reducing the directionality of the non-metallic part of the $\mathrm{Ni}-\mathrm{Al}$ atomic bonding [27]. The work of CSIRO scientists, Forwood and Gibson $[28,29]$, who studied grain boundary structure in cold-rolled and annealed $\mathrm{Ni}_{3} \mathrm{Al}$ with trace additions of boron was quite definitive in showing that the $\mathrm{Ni}_{3} \mathrm{Al}$ lattice was ordered right up to the grain boundaries. Identification of intrinsic and extrinsic grain boundaries in these specimens was made using the image matching technique $[29,30]$. The results showed that the Burgers vectors were always DSC vectors of the ordered $\mathrm{L1}_{2}$ structure, whereas, if the lattice had been disordered near the grain boundaries such dislocations would be expected to adopt the smaller DSC Burgers vectors of the disordered f.c.c. lattice. Hence, the suggestion that disordered f.c.c. material at the grain boundaries is produced by the boron additions and enhances the transmission of slip across grain boundaries, does not apply to these alloys.

\section{TITANIUM ALUMINIDES}

Researchers at CSIRO Division of Materials Science and Technology and at Monash University are both involved in aspects of the development of intermetallic alloys based on the titanium aluminides. These studies range in interest from alloys based around $\mathrm{Al}_{3} \mathrm{Ti}$ to duplex $\gamma / \alpha_{2}-\mathrm{TiAl}$ alloys.

\section{1 $\mathrm{Al}_{3} \mathrm{Ti}(\mathrm{X})$ Alloys}

Both groups of workers have identified the very significant potential of intermetallic alloys based on 
the tri-aluminide $\mathrm{Al}_{3} \mathrm{Ti}$ as lightweight structural materials for high temperature applications. This potential is based on the alloy's low density $\left(3300 \mathrm{Kg} / \mathrm{m}^{3}\right)$, high melting point $(\sim 1615 \mathrm{~K})$ and good oxidation resistance. However, the $\mathrm{DO}_{22}$ structure binary alloy exhibits essentially zero tensile ductility and previous workers had found that, even when alloying is used to promote the $\mathrm{DO}_{22} \rightarrow \mathrm{Ll}_{2}$ transition, the ductility of the resulting cubic alloy was still very low.

\subsubsection{RSP Al-Ti-Ni Alloys}

One approach adopted by the group at Monash University was aimed at producing an Al equivalent of the nickel-based superalloy, i.e. a f.c.c. matrix dispersion hardened with a stable and fine dispersion of coherent intermetallic particles. Much of the work concentrated on an Al-6Ti-1.5Ni (wt\%) alloy and it was found that by RSP an alloy could be produced consisting a mixture of at least two different types of fine $(<100 \mathrm{~nm})$ metastable particles dispersed uniformly within the Al-matrix phase. No preferred orientation relationship between the phases could be detected, suggesting that the metastable particles formed directly from the melt.

Ageing of such alloys in the temperature range 573-773K caused rapid decomposition of the metastable phases accompanied by the uniform precipitation of fine coherent particles of a phase with the $\mathrm{Ll}_{2}$ structure. At $673 \mathrm{~K}$ the maximum hardness associated with the precipitation occurs after $\sim 5$ hours reaching $170 \mathrm{EVH}$. At ageing times beyond this there is a gradual decrease in hardness associated with the slow coarsening of the precipitates and transformation initially to a $\mathrm{DO}_{23}$ structure and finally to the equilibrium phase, $\mathrm{DO}_{22} \mathrm{Al}_{3} \mathrm{Ti}$. At $573 \mathrm{~K}$ the reactions are very slow and even after 720 hours the $\mathrm{Ll}_{2}$ precipitates persist with the peak hardness of 175 EHN being retained. Current work is aimed at optimising the high temperature stability of these alloys and developing processing methods for converting the RSP strip to bulk form without severe diminution of their high temperature mechanical properties.

\subsection{2 $\mathrm{Al}_{3} \mathrm{Ti}-\mathrm{Al}_{3} \mathrm{~V}$ Pseudo-binary Alloys}

An alternative approach used by the Monash group was to investigate alloys based on the pseudo-binary system $\mathrm{Al}_{3} \mathrm{Ti}-\mathrm{Al}_{3} \mathrm{~V}$ [16]. These two phases are exhibit complete miscibility at elevated temperatures and a two phase region involving the intermetallic $\mathrm{Al}_{3}(\mathrm{Ti}, \mathrm{V})$ and the b.c.c. $\beta$ - $(\mathrm{Ti}, \mathrm{V})$ solid solution is also present. In this system careful selection of alloy composition and heat treatment gave rise to alloys with different types of composite microstructures. For the alloy $\mathrm{Al}_{70} \mathrm{Ti}_{10} \mathrm{~V}_{20}$ the as-cast alloy is composed of a eutectic mixture of $\mathrm{Al}_{3}(\mathrm{Ti}, \mathrm{V})$ and the $\gamma$-brass type phase $\mathrm{Al}_{8} \mathrm{~V}_{5}$ (Fig.5a) whereas the alloy $\mathrm{Al}_{55} \mathrm{Ti}_{10} \mathrm{~V}_{35}$ has a dendritic microstructure with the interdendritic phase being $\beta$-(Ti,V) and the remaining areas being a combination of aluminium-rich $\mathrm{Al}_{3}(\mathrm{Ti}, \mathrm{V})$ particles, a hexagonal phase similar in structure to $\alpha_{2}-\mathrm{Ti}_{3} \mathrm{Al}$ and regions where alternating parallel lamellae of the hexagonal phase and twin-related variants of the tetragonal phase, $\mathrm{Ti}_{5} \mathrm{Al}_{11}$. After homogenisation at $1523 \mathrm{~K}$ this alloy consists of a mixture of $\beta-(\mathrm{Ti}, \mathrm{V})$ and the hexagonal $\alpha_{2}-\mathrm{Ti}_{3} \mathrm{Al}$ phases (Fig. 5b).

After suitable heat treatment the $\mathrm{Al}_{70} \mathrm{Ti}_{10} \mathrm{~V}_{20}$ alloy could be converted into the structure shown in Figure $5 \mathrm{c}$ consisting of a uniform distribution of fine $\beta-(\mathrm{Ti}, \mathrm{V})$ particles in the $\mathrm{Al}_{3}(\mathrm{Ti}, \mathrm{V})$ matrix. For the alloy $\mathrm{Al}_{55} \mathrm{Ti}_{10} \mathrm{~V}_{35}$ could be generated by single and multiple stage heat treatments. Figure $5 \mathrm{~d}$ shows the microstructure developed after 1 hour at $1573 \mathrm{~K}$, furnace cooling and ageing 3 hours an $1273 \mathrm{~K}$. The alloy consists entirely of a regular lamellar structure of $\beta-(\mathrm{Ti}, \mathrm{V})$ and twin-related lamellae of the $\zeta-\mathrm{Ti}_{2} \mathrm{Al}_{5}$ phase. This microstructure was shown to have greatly enhanced resistance to crack propagation as indicated by total crack length measurements after indentation to determine Vickers hardness.

\subsection{3 $\mathrm{LI}_{2}$ Structure Al-Ti-TM Alloys}

A potential breakthrough towards improving the ductility of titanium trialuminides was the relatively recent confirmation of original work of Raman and Schubert [31] showing that the brittle $\mathrm{DO}_{22}$ tetragonal crystal structure of the binary $\mathrm{Al}_{3} \mathrm{Ti}$ alloy could be transformed to the potentially more ductile $\mathrm{Ll}_{2}$ cubic structure by the addition of transition metals as ternary alloying elements [1-3]. However, despite the 

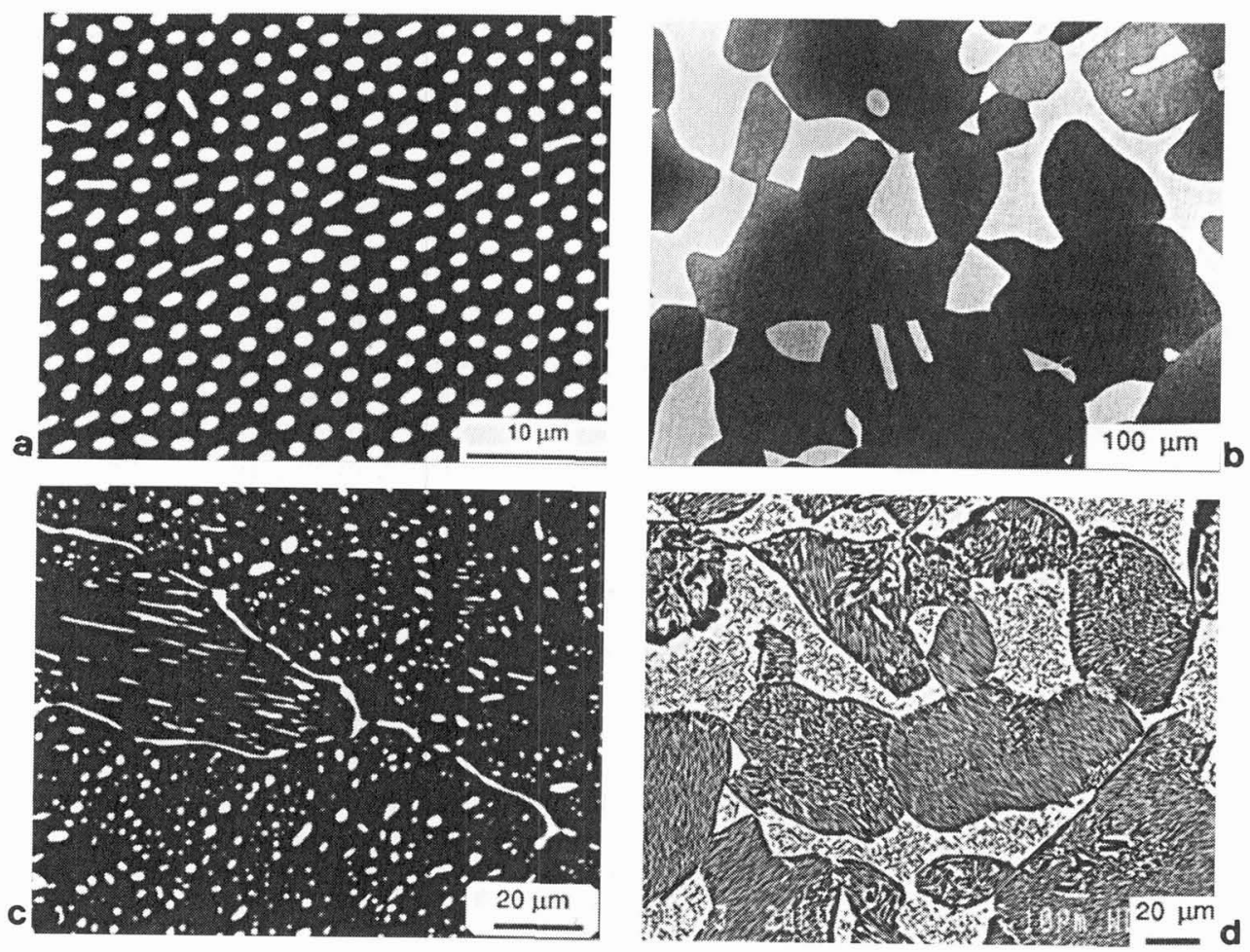

Figure 5. Backscattered electron images of: (a,c) $\mathrm{Al}_{70} \mathrm{Ti}_{10} \mathrm{~V}_{20}$ alloy as cast and after $100 \mathrm{~h}$ at $1073 \mathrm{~K}$ showing $\delta+\zeta$ eutectic and $\delta+\beta(T i, V)$ microsructures respectively: $(\mathrm{b}, \mathrm{d}) \mathrm{Al}_{55} \mathrm{Ti}_{10} \mathrm{~V}_{35}$ alloy homogenised for $24 \mathrm{~h}$ at $1573 \mathrm{~K}$ and after subsequent $100 \mathrm{~h}$ at $1173 \mathrm{~K}$ respectively. (Muddle, Chang and Nie [16]).

fact that $\langle 110\rangle\{111\}$ slip in the $\mathrm{L1}_{2}$ crystal structure provided the five independent slip systems necessary to satisfy von Mises condition for three dimensional plastic deformation, the $\mathrm{L} 1_{2}$ stabilised trialuminides still exhibited only limited ductility in tension at room temperature $(\sim 0.2 \%)$ and failed by transgranular cleavage fracture [31-35]. Based on the Rice-Thomson [36] theory for brittle versus ductile fracture, this behaviour was not unexpected since brittle failure is predicted when $\mathrm{Gb} / \gamma \geq 10$ ( $\mathrm{G}$ is the shear modulus, $\gamma$ the surface energy and $b$ the magnitude of the Burgers vector of the dislocations to be generated at a crack tip). For $\mathrm{Al}_{3} \mathrm{Ti}$, if the dislocations involved have $\mathrm{a}\langle 110\rangle$ Burgers vectors, then $\mathrm{Gb} / \gamma$ $\sim$ 13-19. Even if pairs of a $/ 2\langle 110\rangle$ partial dislocations separated by an antiphase boundary are emitted considered this conclusion is not changed significantly. Hence, the CSIRO researchers concluded that enhancement of ductility in these alloys is more likely to be achieved by the movement of glissile dislocations generated from sources within the crystal. On this basis the phase stability of $\mathrm{L}_{2} \mathrm{Al}-\mathrm{Ti}-\mathrm{TM}$ aluminides $(\mathrm{TM}=\mathrm{Cr}, \mathrm{Ni}, \mathrm{Cu})$ was investigated and the Burgers vectors of dislocations that provide slip during compressive deformation identified.

Typical microstructures of $\mathrm{Cr}$ - and $\mathrm{Ni}$-stabilised Ti-rich alloys are shown in Figure 6. In each system titanium rich alloys of the type $\mathrm{Al}_{64} \mathrm{Ti}_{27} \mathrm{TM}_{9}$ contained families of thin $(001)_{\mathrm{P}} \mathrm{Al}_{2} \mathrm{Ti}$ plates or laths, marked 1, 2 and 3 in Fig. 6a. These laths were parallel to the $(001)_{M},(010)_{M}$ and $(100)_{M}$ planes of the $\mathrm{Ll}_{2}$ matrix respectively and were bounded by pairs of narrowly spaced interfaces which exhibit pendellösung fringes parallel to their line of intersection with the surface of the specimen. For the $\mathrm{Cr}$ stabilised alloy the $(001)_{\mathrm{P}} /\{100\}_{\mathrm{M}}$ interfaces between the $\mathrm{Al}_{2} \mathrm{Ti}$ plates and the $\mathrm{L} 1_{2}$ matrix were coherent in that, as in Figure 6a, they contained no regular arrays of resolvable interfacial dislocations. This observation was consistent with the closely matched lattice parameters of the two phases determined by electron diffraction. Within the limits of experimental error, the $\mathrm{Al}_{2} \mathrm{Ti}$ and the $\mathrm{Ll}_{2}$ structures in the chromium containing alloy had the same value of $a=3.98 \pm 0.02 \AA$. 

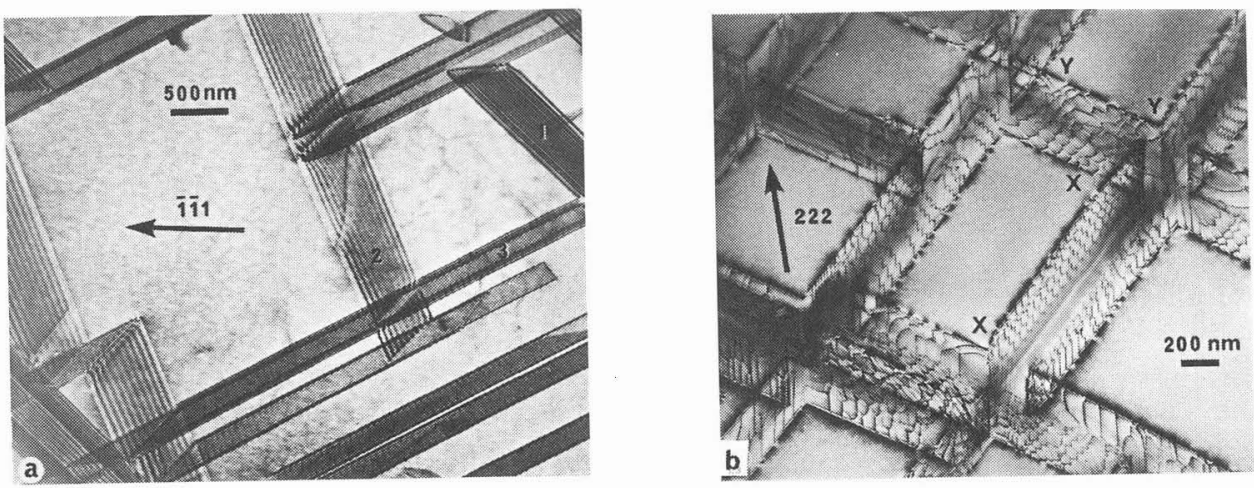

FIGURE 6: Electron micrographs (a)(b) showing three variants of $\mathrm{Al}_{2} \mathrm{Ti}$ plates in the $\mathrm{LI}_{2}$ matrix of $\mathrm{Al}_{64} \mathrm{Cr}_{9} \mathrm{Ti}_{27}$ and $\mathrm{Al}_{64} \mathrm{Ni}_{9} \mathrm{Ti}_{27}$ alloys respectively. The interfacial dislocation networks present on each side of the laths in the $\mathrm{Al}_{64} \mathrm{Ni}_{9} \mathrm{Ti}_{27}$ alloy are clearly visible in (b). (after Forwood and Gibson [7]).

However, for both the $\mathrm{Ni}$ - and the $\mathrm{Cu}$-stabilised alloys, the $(001)_{\mathrm{P}} /\{100\}_{\mathrm{M}}$ interfaces between the $\mathrm{Al}_{2} \mathrm{Ti}$ plates and the $\mathrm{L}_{2}$ matrix were not completely coherent but contained well resolved arrays of interfacial dislocations as shown in Figure $6 \mathrm{~b}$ for an $\mathrm{Al}_{64} \mathrm{Ni}_{9} \mathrm{Ti}_{27}$ alloy. The Burgers vectors , $\left.\mathrm{a} / 2<110\right\rangle_{\mathrm{M}}$, the sign and spacing of the dislocations were all consistent with the measured mismatch in lattice parameters: $a=3.98 \AA$ for the tetragonal $\mathrm{Al}_{2} \mathrm{Ti}$ phase and $a=3.96 \pm 0.02 \AA$ for the $\mathrm{Ni}$ - and Cu-stabilised $\mathrm{Ll}_{2}$ matrix phases. In some cases the $\mathrm{Al}_{2} \mathrm{Ti} / \mathrm{Ll}_{2}$ interfacial dislocation networks contained noticeable irregularities and segments of the $\mathrm{a} / 2\langle 110\rangle_{\mathrm{M}}$ dislocations of screw character were often present. Forwood and Gibson pointed out that such segments provided possible sources for the generation and subsequent movement of $a / 2\langle 110\rangle_{\mathrm{M}} /\{111\}_{\mathrm{M}}$ slip dislocations in the $\mathrm{L} 1_{2}$ matrix and could give rise to enhanced ductility for titanium-rich nickel and copper $\mathrm{L}_{2}$ stabilised trialuminides compared with that exhibited in equivalent chromium stabilised alloys. TEM studies of Ni-stabilised alloys deformed in compression tended to confirm this possibility with active slip bands being generated in regions with a high density of $\mathrm{Al}_{2} \mathrm{Ti}$ laths. Image matching showed that the dislocations within these slip bands were full $a<110>_{M}$ dislocations dissociated into pairs of $\left.1 / 2<110\right\rangle_{M}$ with a separation of only about 3.0nm, i.e effectively moving as full $\langle 110\rangle_{M}$ dislocations [37].

Further, the mechanical properties of the $\mathrm{Cr}-, \mathrm{Ni}$ - and $\mathrm{Cu}$-stabilised $\mathrm{L} 1_{2}$ aluminides, as assessed by compression tests at room temperature as a function of aluminium content for the series of alloys with
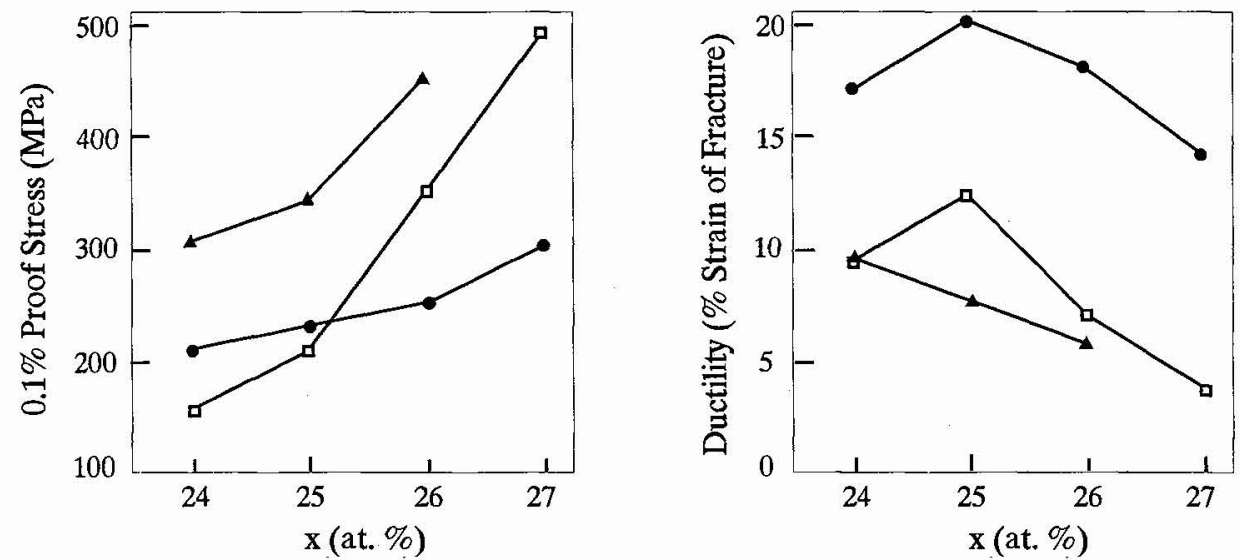

Figure 7. The variation of yield strength and ductility measured in compression tests for series of alloys with compositions $\mathrm{Al}_{91-x} \mathrm{TM}_{9} \mathrm{Ti}_{x}$ where the transition metals (TM) were $\mathrm{Cr}(\bullet), \mathrm{Ni}(\square)$ and $\mathrm{Cu}(\Delta)$. (Forwood and Gibson 17). 
compositions $\mathrm{Al}_{91-\mathrm{x}} \mathrm{TM}_{9} \mathrm{Ti}_{\mathrm{x}}$ indicated that the $\mathrm{Al}_{2} \mathrm{Ti} / \mathrm{L}_{2}$ interfacial dislocations did not act as effective sources of slip dislocations in $\mathrm{Al}_{91-x} \mathrm{TM}_{9} \mathrm{Ti}_{\mathrm{x}}$ alloys. The results obtained showed that, for all three alloy types, excess titanium, with the resulting presence of $\mathrm{Al}_{2} \mathrm{Ti}$ laths, was a potent strengthener. Ductility, however, decreased with increasing titanium content for $x \geq 25$ (where the density of interfacial dislocations was increasing) and the ductility of $\mathrm{Cr}$-stabilised alloys, without the interfacial dislocations, was markedly higher than the $\mathrm{Ni}$ - and $\mathrm{Cu}$-stabilised alloys.

\section{$4.2 \gamma$-TiAl alloys}

The major thrust of titanium aluminides research over the past five years has been in the area of the $\gamma$-TiAl alloys and, in fact, a low pressure turbine with cast turbine blades produced from a $\gamma$-TiAl based alloy (Ti-48 Al-2Cr-2Nb) was reported as assembled ready for engine testing (CF6-80C2) by General Electric [38]. However, despite the progress made with development of the of $\gamma$-TiAl based alloys, there is still a need for alloys with even better ductility and damage tolerance and, for this reason, CSIRO research in the past two years has concentrated on the development of $\gamma$-TiAl alloys with improved room temperature ductility.

For alloys with a $\gamma / \alpha_{2}$ duplex microstructure, intergranular fracture and cleavage are the dominant fracture mechanisms at room temperature [39]. As pointed out by Morris [40], the low ductility for alloys with predominantly the lamellar microstructure, may result from the fact that deformation of these alloys occurs only within the $\gamma$-phase, with little on no transfer of slip across the interface into the $\alpha_{2}$ lamellae resulting in massive pile-ups of dislocations at the $\gamma / \alpha_{2}$ interfaces. The strategy adopted by the group at CSIRO has been to develop new alloy compositions for which transfer of slip activity occurs readily across the $\gamma / \alpha_{2}$ interfaces, so that deformation may proceed across complete $\gamma / \alpha_{2}$ colonies without significant development of dislocation pile-ups and, hence, without the development of crack initiation sites. To achieve this, however, it was considered necessary to gain a detailed understanding of the effects of ternary and higher alloying additions on both the $\gamma$ and $\alpha_{2}$ phases. Studies of partitioning of elements between phases, the site occupancies adopted and the effects of additions on ordering behaviour are being undertaken [5] since each of these has the potential to alter both the microstructure and the mechanical properties of the final alloy. Using information derived from such studies, which are briefly described below, preliminary alloy development trials have revealed several alloys for which transfer of deformation across $\gamma / \alpha_{2}$ and $\gamma / \gamma$ interfaces in the lamellar structure occurs readily with deformation proceeding across complete $\gamma / \alpha_{2}$ colonies. Further detailed TEM analysis of specimens of these alloys deformed to failure in tension has led to a fundamental understanding of the discrete deformation processes involved. These early results indicate that this approach, selective alloying combined with thermal or thermomechanical processing to develop an appropriate microstructure, will produce $\gamma$-TiAl based alloys with superior room temperature tensile ductility without detracting from the alloy's desirable high temperature performance.

\subsubsection{HOLZ and ALCHEMI analysis of Order, Site Occupancy and Element Partitioning in $\gamma$-TiAl}

While, in general, an indication of order parameter can be obtained from matching of CBED contrast in ZOLZ patterns, Rossouw, Forwood and Gibson [5] have recently shown that analysis of the geometry of HOLZ patterns can provide a more direct and sensitive measure of order in $\gamma$-TiAl. They demonstrated that the position of quantum state rings in the HOLZ beams reflects the separation of different branches of the dispersion surface. For some reflections this separation is directly related to the degree of order. The sensitivity of the technique is such that, although both alloys are essentially fully ordered, quite different HOLZ beams are predicted and observed for the near-stoichiometric alloy $\mathrm{Ti}_{49.3} \mathrm{Al}_{50.7}$ and $\mathrm{Ti}_{47} \mathrm{Al}_{53}$.

The standard ALCHEMI technique for analysis of site occupancy in materials has well documented accuracy limitations associated with delocalisation effects and with the need to compare ratios of normalised X-ray counts. Because of this the group at CSIRO has developed a statistical ALCHEMI technique which provides a quantitative estimates of errors, together with higher precision of site occupancy analysis, and less sensitivity to delocalisation effects. 
In practical terms, the technique involves the collection and analysis of $\mathrm{X}$-ray counts for the elements in the alloy over a large number $(n=4582)$ of individual orientations. The data collection is achieved by interfacing the Philips CM30 electron microscope to a computer which automatically controls the tilting and data collection once the initial operation conditions have ben set. Analysis of the data from initial experiments with ternary alloys suggests that realistic errors limits of $5 \%$ in site occupancy can be achieved for additions at the 1-2 at. \% level. Experiments with quaternary and higher element additions are in progress. The same X-ray information can also be used to determine the partitioning of the alloying element between the two phases. However, the CSIRO group has found that standard EDAX techniques applied to the TEM foil specimens provides a better precision.

\section{NOVEL PROCESSING TECHINIQUES}

The research in Australia into novel processing techniques for the production of intermetallics is concentrated into two main areas; mechanically activated alloying and/or reduction $[14,15]$; and rapid solidification processing (RSP) [16,41]. The major materials interest in the mechanical alloying research has been the hard magnetic alloys based on RE-TM alloys and their borides and nitrides. A smaller effort has been made in the development of high melting point intermetallic alloys using this technique [15]. Some hard magnetic alloy development has also been pursued through the RSP route but the strong thrust of the RSP research is concentrated upon the development of structural intermetallics with improved properties as discussed above in the section on $\mathrm{Al}_{3} \mathrm{Ti}(\mathrm{X})$ alloys.

\section{REFERENCES}

[1] West G.W., Philos. Mag. 9 (1964) 979-991, ibid 15 (1967) 855-866.

[2] West G.W., J. Appl. Phys. 39 (1968) 2213-2215.

[3] West G.W., phys. stat. sol. a20 (1973) 647-651.

[4] Morton A.J. and West G.W., "Dislocation generation in Quenched FeAl", 8th. Intnl. Congress of Electron Microscopy, Canberra 1974, J.V. Sanders and D.J. Goodchild Eds., (Australian Academy of Science, Canberra, 1976) pp 460-461.

[5] Rossouw C.J., Forwood C.T. and Gibson M.A., submitted to Philos. Mag.

[6] Forwood C.T., Gibson M.A. and Morton A.J., "Phase Relationships and Mechanical Properties in $\mathrm{Ll}_{2}$ Stabilised $\mathrm{Al}_{3} \mathrm{Ti}$-Based Alloys" , Intnl. Conf. on Light Materials for Transportation Systems, Pohang 1993, N.J. Kim Ed.(Center for Advanced Aerospace Materials, Pohang) pp. 285-293.

[7] Forwood C.T., Gibson M.A., Materials Science Forum - in press.

[8] Margarian A., Dunlop J.B., Day R.K. and Kalceff W., J. Appl. Phys. 76 (1994) 6153-55.

[9] Cadogan J.M., Li H.-S., Margarian A., Dunlop J.B., Ryan D.H., Collocott S.J. and Davis R.L., J. Appl. Phys. 76 (1994) 6138-43.

[10] Ding J., McCormick P.G. and Street R., J. Alloy Compounds 217 (1995) 108-111.

[11] Dexin C.H., Harrison H.B and Reeves G.K., J. Appl. Phys. 63 (1988) 2171-73.

[12] Leckey R., Riley J.D., Johnson R.L., Ley L. and Ditchek B., Jnl. Vac. Sci. Tech. 6 (1988) 63-69.

[13] Ridgway M., Elliman R.G. and Williams J.S., Appl.Phys. Lett. 56 (1990) 2117-19.

[14] Liu Y., Dallimore M.P., McCormick P.G. and Alonso T., Inl. of Magnetism and Mag. Matls. 116 (1992) L320-324.

[15] Calka A. and Radlinski A.P., Scripta metall. 23 (1989) 1497-1501.

[16] Muddle B.C., Chang W.-S. and Nie J.F., "Development of Al-Ti based ternary alloys for elevated temperature applications", Korea-Australia Joint Seminar on Advanced Light Alloys, Taejon 1994, (Rapidly Solidified Materials Research Center, Taejon)pp.85-97.

[17] Fourdeaux A. and Lesbats P., Philos. Mag. 45 (1982) 81.

[18] Kong C.H. and Munroe P.R., Scripta metall. et mater. 28 (1993) 1241

[19] Kong C.H. and Munroe P.R., Scripta metall. et mater. 30 (1994) 1079

[20] Kong C.H. and Munroe P.R., "The Effect of Ternary Additions on the Vacancy Hardening and Defect Structure of FeAl", Processing, Properties and Applications of Iron Aluminides, Schneibel J.H. and Crimp M.A. Eds.,(TMS, Warrendale PA, 1994) 
[21] Kong C.H. and Munroe P.R., Intermetallics 2 (1994) 333-342.

[22] Kong C.H. and Munroe P.R., Scripta metall. et mater. 32 (1995) 469-474.

[23] Aoki K. and Izumi O., Nippon Kinzaku Gakkaishi 43 (1979) 1190.

[24] Liu C.T., White C.L. and Horton J.A., Acta metall. 33 (1985) 213.

[25] Baker I. and Schulson E.M., Scripta metall. 23 (1989) 345.

[26] Baker I., Schulson E.M., Michael J.R. and Pennycook S.J., Philos. Mag. B62 (1990) 659.

[27] Chaki T.K., Philos. Mag. Lett., 61 (1990) 5, ibid 63 (1991) 123.

[28] Forwood C.T. and Gibson M.A., Philos. Mag. A65 (1992) 331-337.

[29] Forwood C.T. and Gibson M.A., Philos. Mag. A66 (1992) 1121-1138.

[29] Head A.K., Humble P., Clarebrough L.M., Morton A.J. and Forwood C.T., Computed Electron Micrographs and Defect Identification (North Holland, Amsterdam 1972).

[30] Clarebrough L.M. and Forwood C.T., Electron Microscopy of Interfaces in Metals and Alloys (Adam Hilger, Bristol 1991).

[31] Zhang, S., Nic, J.P., and Mikkola, D.E.: Scripta Metall. 24 (1990) 57.

[32] Kumar, K.S., and Brown, S.A.: Philos. Mag. 62 (1992) 91.

[33] Kumar, K.S., and Brown, S.A.: Acta Metall. 40 (1992) 1923.

[34] Schneibel, J.H., Horton, J.A., and Porter, W.D.: Mater. Sci. Eng. A152 (1992) 126.

[35] Chen, X., Wu, X., Chen, S., and Hu, G.: Scripta Metall. 26 (1992) 1775.

[36] Rice, J.R., and Thomson, R.: Philos. Mag. 29 (1974) 73.

[37] Forwood C.T. and Gibson M.A., private communication.

[38] Austin C.M. and Kelly T.J., "Development and Implementation Status of Cast Gamma Titanium Aluminide", Structural Intermetallics - Dariola et al. Eds.(TMS 1993) p.143.

[39] James A.W. and Bowen P., Mater. Sci. Eng. A153 (1992) 486.

[40] Morris M.A., "Anomalous Strengthening in TiAl Alloys - Dislocation Mechanisms related to Alloy Composition", Structural Intermetallics - Dariola et al. Eds.(TMS 1993) p.257.

[41] Cadogan J.M., Li H.-S., Davis R.L., Margarian A., Collocott S.J., Dunlop J.B. and Gwan P.B., J. Appl. Phys. 75 (1994) 7114-16. 